\title{
https://doi.org/10.48009/1_iis_2006_56-61 \\ BALANCING THE NEED FOR CONCEPTS AND APPLICATIONS IN MIS EDUCATION: AN EXPLORATORY EMPERICAL MODEL
}

\author{
Junwei Guan, Indiana University South Bend, USA, jguan@iusb.edu \\ Ganesh Vaidyanathan, Indiana University South Bend, USA, gvaidyan@iusb.edu \\ Shi Zheng, Renmin University, Beijing, China, zhengshi1974@ hotmail.com \\ Keith Smith, Indiana University South Bend, USA, ksmith1@iusb.edu
}

\begin{abstract}
Perceived learning in MIS depends on gaining knowledge from MIS concepts and by using MIS application tools. MIS education in undergraduate curriculum of a business school needs to foster both concepts and applications dimensions of learning. There is also a need to understand the implications of these two dimensions in MIS education. This study explores these two dimensions of MIS education in undergraduate business by devising a framework and using the framework to incorporate a research model which is then estimated by using survey data. The results show that concepts as well as applications are essential in undergraduate MIS education in a business school.
\end{abstract}

Keywords: MIS Knowledge, Concept, Application, MIS Education

\section{INTRODUCTION}

In a recent survey, over 61 percent of the 580 chief information officers felt that college graduates are poorly prepared to work in the real world of business Information Technology [8]. In the same survey, it was pointed out that although many are technologically savvy, 74 percent of the CIOs surveyed believed they lacked skills in areas such as project management, and 71 percent considered them woefully unprepared for business operations. The Management Information Systems (MIS) education in business schools should offer a good balance of technology and business. MIS education creates a pedagogically effective environment even superior to alternative modes of learning and instruction [2]. However, students frequently have difficulty integrating and applying knowledge from various domains in practical situations [5]. Therefore, universities are being challenged to produce job candidates with skills and knowledge that are in demand [6], the capacity to make decisions and solve problems, and the ability to apply knowledge to the workplace [11].
In order for MIS programs to rise to the occasion of providing these skills to their students, there is a need for a structured MIS education [12]. The need for MIS education has two components. First, the students need to learn about fundamental concepts, theories, and principles that underlie MIS phenomena [12]. The content should cover material associated with the structure and functions of hardware and system software, principles of good program design and testing, design and implementation of databases and knowledge bases, fundamentals of security, and user-computer interfaces [12]. The second component of the curriculum should be comprised of a set of subjects that are vocational in nature and that provide students with knowledge about and experience with current MIS phenomena, for example, widely used application packages [12].

Information technologies have already brought many capabilities to the classroom. Technology, when properly applied, can provide an effective means for learning. Technology has to be used to augment the skills that are necessary to convert data into information and transform information into knowledge which may be used to apply skills [4]. How do undergraduate students in business students understand MIS concepts? Is there a need for application-oriented training in the MIS curriculum? It is difficult to understand how students can obtain a deep understanding of and facility with higher-level skills without having first acquired a good knowledge of fundamental MIS concepts [12]. To acquire knowledge of concepts, they need to be provided context using applications since teaching these concepts, theories, and principles in abstract is problematical and students are unlikely to engage meaningfully and knowing how to apply them in workplace successfully [12]. This brings out an important research issue to understand the relationships between students applying their learning of concepts in MIS education. We begin this quest by developing a research framework in undergraduate business education in MIS concepts and applications in this study. 
The contributions of this study are as follows. First, we propose a framework for MIS education that involves student perceived MIS knowledge gained in learning MIS concepts and applications in undergraduate business curriculum. Second, we use the self evaluation survey of students to explore how concepts and applications may be related in understanding MIS. The paper is organized as follows. In the next section, we develop and present a research framework on undergraduate MIS education in business and student perceptions. In Section 3 we use the framework to explore how students in MIS undergraduate education understood the material. In Section 4 we conclude with implications and directions for future research.

\section{FRAMEWORK}

The futures for MIS jobs remain a prominent feature of the U.S. economy [10]. Yet success in today's job market depends very much on increasingly effective and efficient learning as the body of relevant information and knowledge escalates [1]. However, universities have limited resources [6] to teach using a variety of MIS tools and applications. However, universities can use commonly used application packages such as Microsoft Excel spreadsheets and Microsoft Access databases to teach the concepts.

Spreadsheets have become one of the most popular and ubiquitous software packages. A research article noted that managers often become so comfortable with spreadsheets that they are reluctant to adopt other software packages even if the other packages are more suitable for specific applications [3]. Although the basic spreadsheet interface has not changed much over the past ten years, the power and functionality has grown enormously, resulting in a powerful modeling and programming environment that MIS educators could only dream about a decade ago. MIS students need to know databases as they have to access data from various sources in their future workplaces. Data is the basis of decisionmaking and the core entity in organizations. Everything from innovative product designs to competitive moves rely on knowledge [7], and without understanding data or database systems, it is difficult to derive knowledge [9].

We use a framework as illustrated in Figure 1 that has been followed in our university for some time. The teaching in MIS starts with basic understanding of Microsoft Windows that includes fundamentals of computer hardware and software, use of packaged programs in areas such as word processing, spreadsheets, database management, communications, graphics, the role and impact of computers in society. This "hands-on" course is designed for people with little or no computer experience.

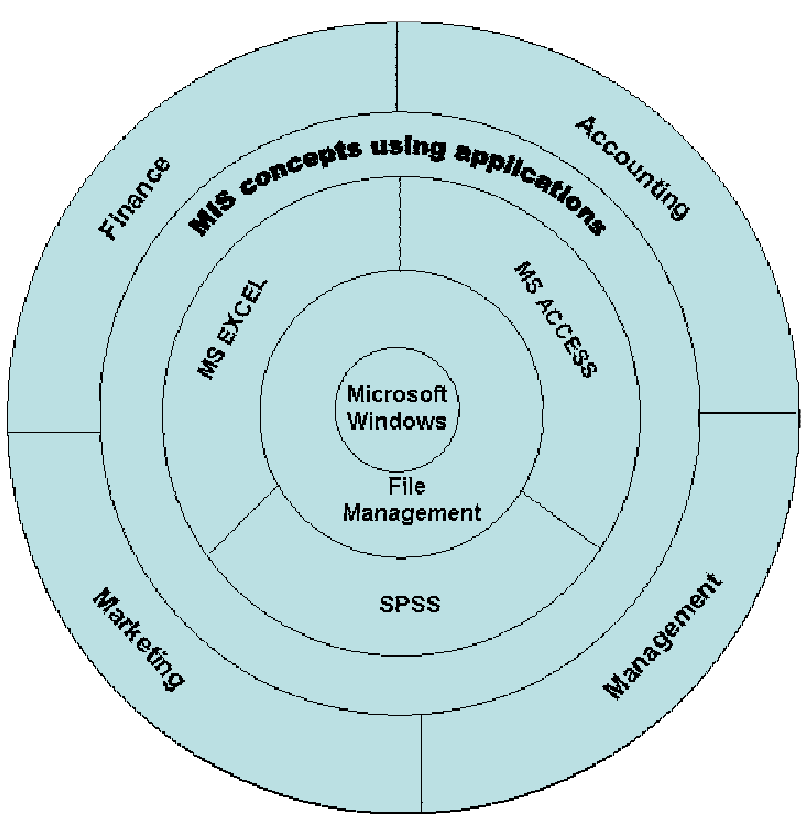

Flgure 1 MIS pedagogy framework

The students use this preliminary course as a prerequisite for the next level course that teaches computer concepts in business. File management is recognized as an important part of learning computers in business. The use of files, directory structures, and their management is taught using Microsoft Windows. The students also learn how to manage the files using the easy, user-friendly file management system and gain "hands-on" practice with how to use the simple file management system, use the advanced features of the file management system, use advanced options to manage files, understand and use the various network drives and how to maneuver the drives to obtain the performance needed, and understand and use various short cuts for quick access to various applications and files. In this course, Microsoft EXCEL, Microsoft ACCESS, and SPSS are taught extensively. This course also introduces students to digital computers, hardware, networking concepts, software, Internet, and databases, and emerging technologies in MIS.

In MIS education structure, we use a third course to help students gain an understanding of the business applications of information systems and how they can support a firm's business processes, managerial 
decision making, and strategies for competitive advantage.

The components of real world information systems and how IT professionals use hardware, software, data, and networks as resources to perform input, processing, output, storage, and control activities that transform data resources into information products as well as several major types of information systems from practical experiences with business organizations in the real world are taught as concepts. The course also explores how businesses use Internet and other IT systems to support their business processes as well as developing and implementing IT strategies and systems using several strategic planning and application development approaches. To support the learning of these concepts, students use spreadsheets and databases to model practical financial, accounting, managerial, and marketing functions. This course stands as a foundation to other higher level courses in accounting, finance, management, and marketing.

In the next section, we explore a research model to discuss how students reflected on learning applications and how applications as well as concepts helped them to understand and gain MIS knowledge to prepare them for higher level classes as well as preparing them for future jobs.

\section{EXPLORATORY MODEL AND HYPOTHESES}

This section illustrates an exploratory model using the framework described in the previous section. Figure 2 illustrates the exploratory model.

\section{Applications}

The applications considered in this research are spreadsheet software, personal database software word processing software, personal email software, presentation software, and a statistical package. These are commonly used applications in the business world.

All these software packages are covered in our MIS courses, but they receive different emphasis in different courses. The first MIS introduction course focuses on basic applications such as file management, word processing, email, and presentation. Advanced applications such as spreadsheet and personal database, are taught in the second MIS course. In the last course, students utilize IT knowledge gained in previous courses to analyze complicated business cases and make professional presentations. Although software skills are covered in three separate courses, we put great effort into coordination to eliminate the gap between classes. Instructors of these courses meet frequently to discuss the status of the curriculum and student performance. Considerable amount of time are set aside at the beginning of advanced courses to review knowledge covered before. Given that we have a large number of nontraditional students who might have taken the lower level class years ago, thorough review before embarking on new material proved to be extremely important. The MIS faculties also talk to faculties in other disciplines regularly to update them with the MIS curriculum status and to get input from them. Since all business majors take these MIS courses, we think it is very important to make sure that students not only learn the IT skills but also be ready to apply the knowledge in their majors.

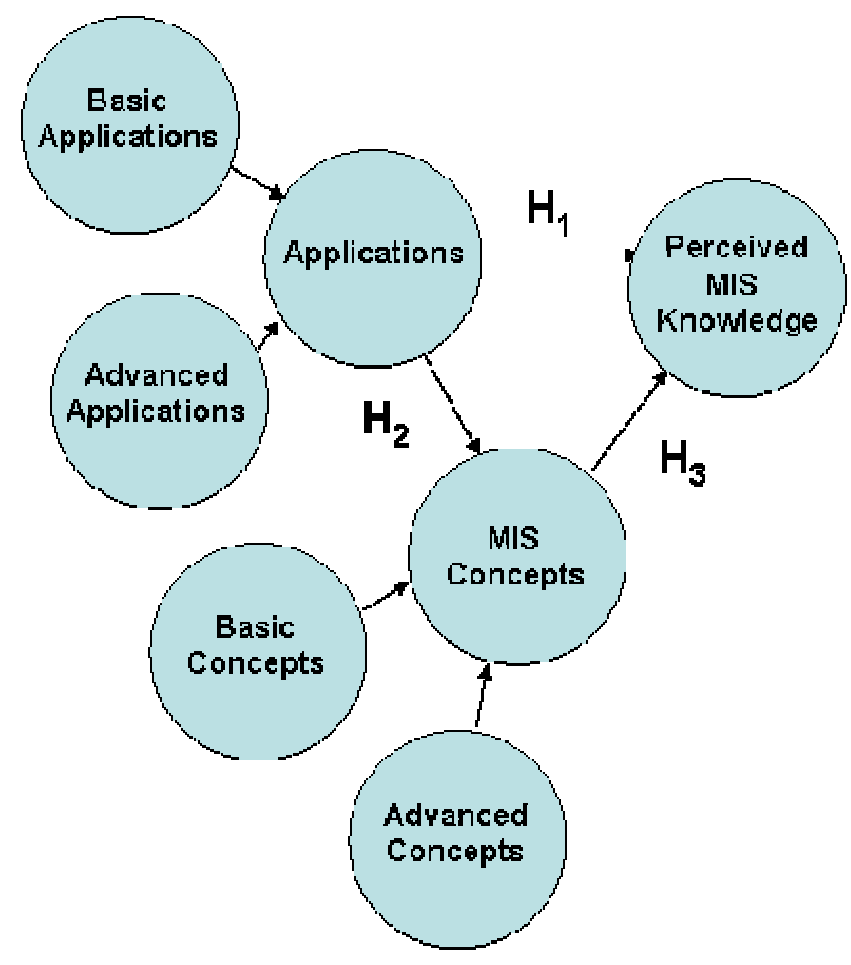

Figure 2 Research Model

\section{MIS Concepts}

Our MIS concept education mainly focuses on explaining IT terms and how they are used in business. MIS concepts can be divided into two groups as well: basic concepts and advanced concepts. We consider IT concepts related to 
everyday business as basic concepts, such as Transaction Processing System (TPS), Management Information Systems (MIS), and Decision Support Systems (DSS). Most businesses nowadays have these systems in one form or another. Some of them have these systems as part of an integrated IT package, while others use generic tools (such as Excel) to build their own that are comparatively rudimentary but are used to accomplish similar tasks. Advanced concepts covered in our courses represent the latest and/or the most powerful tools in business technology, such as Enterprise Resource Planning (ERP), Customer Relationship Management (CRM), and Executive Information Systems (EIS). Because of the opportunities and challenges the advanced systems present, they have received a lot of attention in recent years, and have been the focus of many debates. Although many of them are new to the market and are still under development, we believe they represent the future and consider it important to introduce them to the students. Because students only start learning spreadsheet and database in the second MIS course, concepts are primarily introduced by lectures and business cases. Most "hands-on" exercises in this course are only for the purpose of illustrating operational knowledge of the software. But beginning in the third course, lots of "hands-on" exercises will be utilized to reinforce the concepts. This, we believe, is where students get the real understanding of how these systems work

\section{MIS Knowledge}

We believe it is appropriate to let the students understand the fundamental operational knowledge first and then expose them to the more complicated management issues. We cover a broad range of IT management topics, from MIS strategy to MIS ethics. We try to gear the content to fit all business majors, not only just MIS majors. The focus is not technical details, but what problems arise in MIS and how to deal with them. Topics covered include IT strategy, ethics, security, implementation, organizational behavior, IT induced change, and business process reengineering.

Since learning from both concepts and applications are essential in MIS education, we propose the following hypotheses:

H1: Learning MIS applications has positive association with perceptions of understanding MIS knowledge.

H2: Learning MIS applications has positive association with learning MIS concepts.

\section{H3: Learning MIS concepts has positive association with perceptions of understanding MIS knowledge.}

\section{Method}

Data used in this research were collected by surveys conducted from March 2005 to March 2006. Surveys were given to business students in a public university in Midwest USA. All participants had completed all the required MIS courses before taking the survey. A total of 189 students completed the survey. The questionnaire was developed using a Likert scale of one to five with one being not important at all and five being extremely important. The descriptive statistics are shown in Table 1.

Table 1. Descriptive Statistics

\begin{tabular}{lll}
\hline Variable & Mean & Standard Deviation \\
\hline$C O N^{1}$ & 4.7 & 0.767 \\
$A P P^{2}$ & 5.3 & 1.218 \\
$M_{\text {IIS }} \mathrm{KNOW}^{3}$ & 4.6 & 1.132 \\
\hline
\end{tabular}

Note:

1. $C O N$ is calculated as the average response to knowledge gained on TPS, MIS, DSS, ERP, CRM and KMS

2. APP is calculated as the average response to knowledge gained on word processing, presentation, email, spreadsheet, personal database, and statistical package.

3. MIS_KNOW is calculated as the average response to knowledge gained in IT strategy, ethics, security, implementation, organization behavior, IT induced change, and business process reengineering.

\section{RESULTS AND DISCUSSION}

Simultaneous equation modeling was used to analyze the data, and the model is specified as follows:

$$
\begin{aligned}
& C O N=\beta_{10}+\beta_{11} A P P+\varepsilon_{1} \\
& M I S_{-} K N O W=\beta_{20}+\beta_{21} A P P+\varepsilon_{2} \\
& M I S_{-} K N O W=\beta_{30}+\beta_{31} C O N+\varepsilon_{3}
\end{aligned}
$$

where,

CON $=$ average perceived importance of IT concepts in learning,

APP $=$ average perceived importance of IT applications in learning,

MIS_KNOW = average perceived importance of MIS knowledge in learning

$\mathcal{E}_{i}=$ disturbance terms $(\mathrm{i}=1,2,3)$ 
In Table 2, we present the results of estimation by using the 2-stage least square method. The coefficients of all variables are significant at the 0.001 level, which means all our hypotheses are well supported. It shows that students perceive IT applications, concepts, and MIS knowledge as positively related entities, although they are taught in different course. The results also show that learning IT applications helps to learn IT concepts. The results also indicate that learning IT applications as well as concepts has a positive impact on learning MIS knowledge.

Table 2. Regression Results

\begin{tabular}{|c|c|c|c|c|}
\hline Model & $A P P=\beta_{10}+\beta_{11} C O N+\varepsilon_{1}$ & & & \\
\hline $\begin{array}{l}\text { Adj. R-square } \\
0.402\end{array}$ & $\begin{array}{l}\text { Variable } \\
\text { CON }\end{array}$ & $\begin{array}{l}\text { Coefficient } \\
\beta_{11}\end{array}$ & $\begin{array}{l}\text { Estimate } \\
0.794\end{array}$ & $\begin{array}{l}\text { t-statistic } \\
7 * * *\end{array}$ \\
\hline Model & $M I S_{-} K N O W=\beta_{20}+\beta_{21} A P P+\varepsilon_{2}$ & & & \\
\hline $\begin{array}{l}\text { Adj. R-square } \\
0.417\end{array}$ & $\begin{array}{l}\text { Variable } \\
A P P\end{array}$ & $\begin{array}{l}\text { Coefficient } \\
\beta_{21}\end{array}$ & $\begin{array}{l}\text { Estimate } \\
0.746\end{array}$ & $\begin{array}{l}\text { t-statistic } \\
7.11 * * *\end{array}$ \\
\hline Model & $M I S_{-} K N O W=\beta_{30}+\beta_{31} C O N+\varepsilon_{3}$ & & & \\
\hline $\begin{array}{l}\text { Adj. R-square } \\
0.391\end{array}$ & $\begin{array}{l}\text { Variable } \\
\text { CON }\end{array}$ & $\begin{array}{l}\text { Coefficient } \\
\beta_{31}\end{array}$ & $\begin{array}{l}\text { Estimate } \\
0.939\end{array}$ & $\begin{array}{l}\text { t-statistic } \\
6.89 * * *\end{array}$ \\
\hline
\end{tabular}

***: significant at the 0.001 level.

\section{LIMITATIONS AND FUTURE RESEARCH}

This study revealed that learning of concepts as well as learning applications leads to knowledge gained in MIS education, particularly in the baccalaureate education in business. This is an exploratory study on how MIS education needs to focus using students' evaluation. In this study, we do not consider project management and other skills needed by MIS professionals. We can steer this research in a number of directions. Concepts are difficult to understand without examples and applications. Furthermore, it is very difficult for students to apply what they have learnt as concepts without applications [5]. We would like to extend this study to understand the mediating effects of concepts and applications to gain MIS knowledge. The study can be estimated using structural equation modeling to determine how applications interact with concepts and how they in turn relate to self-efficacy.

We are in the process of collecting more data to make the model more robust. The model can be extended to other software applications that are being taught in universities, for example, enterprise resource planning software. MIS is a dynamic field and this dynamic may be included in the model to understand how concepts may be taught in this changing field.
The study has a few limitations as well. First, respondents to our survey were primarily students. We are planning to survey practitioners and business school faculty to understand their perspectives about MIS education. Second, this study is restricted to perceptions of student self efficacy. The study may be extended and tested to acceptance of learning concepts through applications from the students' point of view as well. Further studies might explore these areas of research to benefit students and their potential in workplaces.

\section{REFERENCES}

1. Alavi, M. (1994). Computer mediated collaborative learning: An empirical evaluation. MIS Quarterly, 18, 159-174.

2. Alavi, M., Yoo, Y., \& Vogel, D.R. (1997). Using information technology to add value to management education. Academy of Management Journal, 40 (4), 1310-1333.

3. Chan, Y.E. \& V.C. Storey (1996). The use of spreadsheets in organizations: Determinants and consequences. Information \& Management, 31, 119-134.

4. Hardin, J. \& Ziebarth, J. (2000). Digital technology and its impact on education, The Future of Networking Technologies for Learning, Available: http://www.ed.gov/ 
TechnologyFutures/hardin.html (retrieved on February 20, 2006)

5. Kelly, J.B. (1982). A primer on transfer of training. Training and Development Journal, 36, 102-106.

6. Leitheiser, R.L. (1992). MIS skills for the 1990s: A survey of MIS manager's perceptions. Journal of Management Information Systems, 9(1), 6991.

7. Markus, M.L., Majchrzak, A., \& Gasser, L. (2002). Design theory for systems that support emergent knowledge processes. MIS Quarterly, 26 (3), 179-212.

8. Tsang, S. (2006). What CIOs need from IT schools. The Age, May 13, 2005.
9. Turban, E., Leidner, D., McLean, E., \& Wetherbe, J. (2006).Information Technology for Management: Hoboken, NJ: John Wiley \& Sons, Inc.

10. U.S. Department of Labor. (2004). IS/IT occupations in the U.S. economy. Occupational Outlook Quarterly, 47(4).

11. Walker, R.H., Hanson, D., Nelson, L., \& Fisher, C. (1998). A case for more integrative marketing education. European Journal of Marketing, 32 (9/10), 803-812.

12. Weber, R. (2004). Editor's comments: Some implications of the year-2000 era, dot-com era, and offshoring for information systems education. MIS Quarterly, 28(2), iii-xi. 